\title{
An Efficient Synthesis of 1,8-Dioxo-Octahydroxanthenes Derivatives Using Heterogeneous Ce-ZSM-11 Zeolite Catalyst
}

\author{
Rameshwar R. Magar, Ganesh T. Pawar, Sachin P. Gadekar, Machhindra K. Lande* \\ Department of Chemistry, Dr. Babasaheb Ambedkar Marathwada University, Aurangabad (M.S.), \\ 431004, India
}

Received: $5^{\text {th }}$ January 2018; Revised: $25^{\text {th }}$ May 2018; Accepted: $7^{\text {th }}$ May 2018;

Available online: $14^{\text {th }}$ November 2018; Published regularly: December 2018

\begin{abstract}
The Ce-ZSM-11 zeolite has been used as an efficient catalyst for the one pot synthesis of 1,8-dioxooctahydroxanthene derivatives from aromatic aldehyde and 5,5-dimethyl-cyclohexane-1,3-dione under reflux condition. The catalyst was characterized by Powder X-ray diffraction (XRD), Scanning Electron Microscopy (SEM), Energy Dispersive Spectroscopy (EDS), Fourier Transform Infrared Spectroscopy (FTIR), Brunauer-Emmer-Teller (BET) surface area analysis, and Temperature Programmed Desorption (TPD) techniques. This method provides several advantageous such as use of inexpensive catalyst, simple work-up procedure, high yield of desired product and reusability of catalyst. Copyright (C) 2018 BCREC Group. All rights reserved
\end{abstract}

Keywords: Ce-ZSM-11 Zeolite; 1,8-Dioxo-octahydroxanthene; Aromatic Aldehyde; 5,5-Dimethylcyclohexane-1,3-dione

How to Cite: Magar, R.R., Pawar, G.T., Gadekar, S.P., Lande, M.K. (2018). An Efficient Synthesis of 1,8-Dioxo-Octahydroxanthenes Derivatives Using Heterogeneous Ce-ZSM-11 Zeolite Catalyst. Bulletin of Chemical Reaction Engineering \& Catalysis, 13 (3): 436-446 (doi:10.9767/bcrec.13.3.2062.436-446)

Permalink/DOI: https://doi.org/10.9767/bcrec.13.3.2062.436-446

\section{Introduction}

The significant challenge in the synthetic chemistry is to develop environmentally benign, efficient and economical methods for the synthesis of biologically active compounds [1]. Multi-component reactions $(\mathrm{MCRs})$ have become one of the best tools for modern synthesis of chemically and biologically important compounds because of their high atom economy, simple procedure and excellent yields [2-4]. Xanthene and its derivatives have received con-

\footnotetext{
* Corresponding Author.

E-mail: mkl_chem@yahoo.com (M.K. Lande)

Telp: +910240 2403311, Fax: +91 02402403335
}

siderable attention in the field of pharmaceutical and medicinal chemistry because of their wide range of biological and pharmacological properties such as antibacterial [5], analgesic [6], anti-inflammatory [7], and anti-cancer properties [8]. In addition, these heterocyclic compounds can be used as $\mathrm{pH}$-sensitive fluorescent materials [9], in laser technology [10], and as luminescent dyes [11]. In view of this wide applicability of xanthene derivatives, the development of synthetic procedure is important. Several methods that have been reported for the synthesis of xanthene derivatives catalyzed by $\mathrm{Fe}_{3} \mathrm{O}_{4}$ nanoparticle [12], $\mathrm{SiCl}_{4}$ [13], $\mathrm{CaCl}_{2}$ [14], Imidazol-1-yl-acetic acid [15], CAN 
[16], DSIMHS ionic liquid [17], $\mathrm{ZnO}$ nanoparticle [18], Ru@SH-MWCNT [19], and Fe-Cu/ZSM-5 [20] catalyst. However, some of these protocols suffer from one or more drawbacks, such as: use of hazardous solvent, high temperature, long reaction time, tedious workup procedure and use of expensive catalyst. Therefore, the development of alternative route for the synthesis of 1,8-dioxo-octahydroxanthene derivatives is highly desirable.

Zeolites are microporous, crystalline, aluminosilicate compounds composed of staggered framework of $\left[\mathrm{AlO}_{4}\right]^{5^{-}}$and $\left[\mathrm{SiO}_{4}\right]^{4^{-}}$tetrahedra which generates a network of pores and cavities having molecular dimensions. They finds extensive applications in heterogeneous catalysis due to their tunable pore sizes, high surface area, framework acid/base properties and provides greener alternatives to homogeneous catalysts [21]. ZSM-11 belongs to pentasil family of zeolites which has straight micropore with MEL framework topology [22]. ZSM-11 possesses unique properties, such as high-surface area, acidity and shape selectivity characters [23] hence it has been utilized as heterogeneous catalyst for conversion of methanol to hydrocarbon, aromatization and isomerization of 1-hexene, cracking of pentene to $\mathrm{C}_{2}$ - $\mathrm{C}_{4}$ olefins and conversion of methanol into light olefins [24-27]. The transition metal doped ZSM-11 possesses greater Lewis acidity compared to parent ZSM-11 and showed better catalytic performance in some reaction such as degradation of Dichlorvos, decomposition of $\mathrm{N}_{2} \mathrm{O}$, conversion of methane $\left(\mathrm{C}_{1}\right)$ into higher hydrocarbons, dehydrogenation-aromatization of alkane and decomposition of low-density polyethylene [28-32].

Thus, in continuation to our research work $[33,34]$, we report the synthesis, characterization, and catalytic application of Ce-ZSM-11 zeolite catalyst for one pot synthesis of 1,8-dioxo-octahydroxanthene derivatives via cyclocondensation of aromatic aldehyde, 5,5 dimethyl-cyclohexane-1,3-dione using catalytic amount of Ce-ZSM-11 under reflux condition in water as solvent (Scheme 1).

\section{Materials and Method}

\subsection{Chemicals and Instrument}

All the chemicals were purchased from Merck, Avra, and Spectrochem and were used without purification. Thin layer chromatography was performed on Merck pre-coated silica gel $60 \mathrm{~F}_{254}$ aluminum sheets as adsorbent. Melting points were taken in an open capillary and are uncorrected. FT-IR spectra were recorded on Thermo Nicolet; Avatar 370. ${ }^{1} \mathrm{H}$ NMR spectra were recorded on a $400 \mathrm{MHz}$ using DMSO- $d_{6}$ as solvent and tetramethylsilane (TMS) as an internal standard. The X-ray diffraction (XRD) patterns were recorded on Bruker AXS D8 Advance X-ray diffractometer using monochromatic $\mathrm{Cu}-\mathrm{Ka}$ radiation having wavelength $\lambda=1.5406 \AA$. Scanning Electron Microscope image (SEM) was obtained on JS$6390 \mathrm{LV}$ operated at $30.0 \mathrm{KV}$. Surface area and porosity (BET) of catalyst was measured on micro-meritics, ASAP 2010 instrument. Temperature Programmed Desorption (TPD) ammonia was measured on Micromeritics instrument.

\subsection{Synthesis of ZSM-11 Zeolite Catalyst}

The ZSM-11 zeolite was synthesized by hydrothermal method. Tetraethyl orthosilicate and sodium aluminate were used as silicon and aluminum source respectively and tetra propyl ammonium bromide was used as structure directing agent. In a typical synthesis, tetraethyl orthosilicate $(20.8 \mathrm{~g})$ was mixed with $50 \mathrm{~mL}$ deionized water and stirred at room temperature for $2 \mathrm{~h}$ to obtain silica sol. Sodium aluminate $(0.246 \mathrm{~g})$ and $2 \mathrm{~g} \mathrm{NaOH}$ were dissolved in 50 $\mathrm{mL}$ deionized water and added drop-wise to stirred solution of silica sol. Tetra propyl ammonium bromide $(2 \mathrm{~g})$ was dissolved in $20 \mathrm{~mL}$ of deionized water and added drop wise to above solution. The resulting mixture was stirred at room temperature for $12 \mathrm{~h}$. The viscous homogeneous gel was transferred into Teflon lined stainless steel autoclave and treated hydrothermally under static condition and autogenous pressure at $150{ }^{\circ} \mathrm{C}$ for $24 \mathrm{~h}$. The solid<smiles></smiles>

1<smiles>CC1(C)CC(=O)CC(=O)C1</smiles>

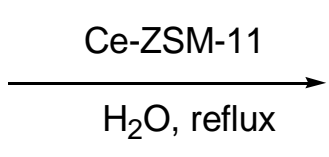

$\mathrm{H}_{2} \mathrm{O}$, reflux

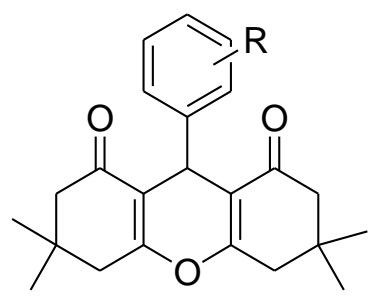

3a-k

Scheme1. Synthesis of 1,8-dioxo-octahydroxanthene derivatives 
product was collected, filtered and washed with deionized water. Finally, it was dried in an oven and calcined at $550{ }^{\circ} \mathrm{C}$ for $4 \mathrm{~h}$ in muffle furnace.

For the enhancement of acidic strength in the catalyst, the cerium ion containing ZSM-11 was prepared by ion exchange method. In this procedure $2 \mathrm{~g}$ ZSM-11 zeolite and $20 \mathrm{~mL} 0.1 \mathrm{M}$ ceric ammonium nitrate solution were stirred at $50{ }^{\circ} \mathrm{C}$ for $12 \mathrm{~h}$. The resulting product (Ce-ZSM-11) was filtered, washed with deionized water and dried in oven at $100{ }^{\circ} \mathrm{C}$ for $5 \mathrm{~h}$.

2.3 General Procedure for the Synthesis 1,8dioxo-octahydroxanthene Derivatives:

To a mixture of aromatic aldehyde (1 mmol), 5,5 dimethyl-cyclohexane-1,3-dione (2 $\mathrm{mmol})$ and Ce-ZSM-11 catalyst $(0.1 \mathrm{~g})$ in water (10 $\mathrm{mL}$ ) as solvent were added and refluxed for the time shown in (Table 4). The progress of the reaction was monitored by TLC (petroleum ether: ethyl acetate $=7: 3$ as eluent). After completion of the reaction, the reaction mixture was filtered, the catalyst was separated and the crude product obtained was recrystallized from ethanol to afford pure product (3a-k) and representative compound characterized by FT-IR, ${ }^{1} \mathrm{H}$, and ${ }^{13} \mathrm{C}$ NMR spectroscopy.

2.4 Selected Spectroscopic Data 3,3,6,6 tetramethyl-9-(3-nitro-phenyl)-3,4,5,6,7,9hexahydro-2H-Xanthene-1,8-dione (3c)

FT-IR (KBr, cm-1): 2955, 2874, 1708, 1584, 1452, $1363,{ }^{1} \mathrm{H}$ NMR (400 MHz, DMSO-d6): $\delta(\mathrm{ppm})=8.05(\mathrm{~s}, 1 \mathrm{H}), 7.97(\mathrm{~d}, \mathrm{~J}=8.1 \mathrm{~Hz}, 1 \mathrm{H})$, $7.63(\mathrm{~d}, \mathrm{~J}=7.7 \mathrm{~Hz}, 1 \mathrm{H}), 7.48$ (t, J= $7.9 \mathrm{~Hz}, 1 \mathrm{H})$, $4.67(\mathrm{~s}, 1 \mathrm{H}), 2.56(\mathrm{~s}, 4 \mathrm{H}), 2.09(\mathrm{~s}, 4 \mathrm{H}), 1.08(\mathrm{~s}$,

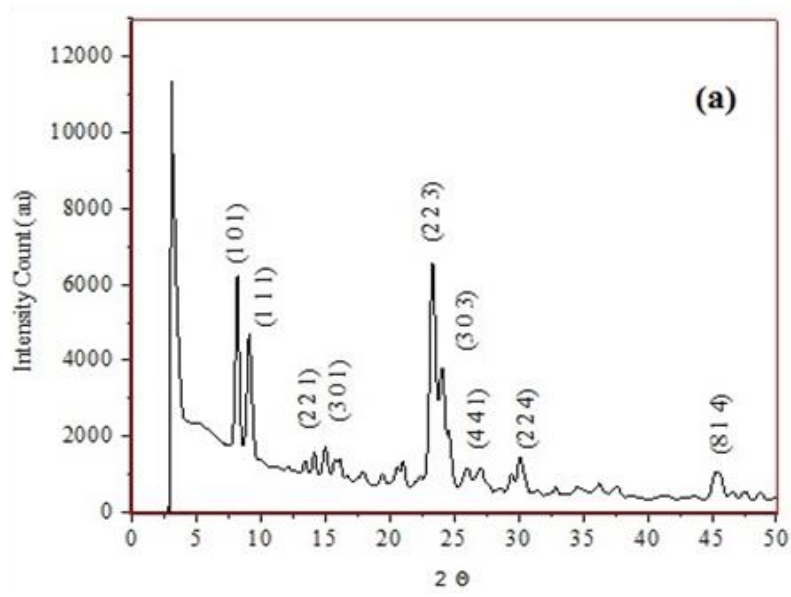

$6 \mathrm{H}), 0.9(\mathrm{~s}, 6 \mathrm{H}),{ }^{13} \mathrm{C}$ NMR $(400 \mathrm{MHz}, \mathrm{DMSO}-$ d6): 26.61, 28.61, 31.63, 39.57, 49.94, 113.48, $121.17,122.70,129.08,134.55,146.27,147.39$, 163.14, 195.74 .

\section{Results and Discussions}

\subsection{Catalyst Characterizations}

\subsubsection{Powder X-ray diffraction analysis}

X-ray diffraction pattern of parent ZSM-11 and Ce-ZSM-11 are given in Figure 1 which shows intense peaks at $2 \theta^{\circ}=8.17,9.08,14.15$, $15.00,23.30,24.04,26.05,27.06,29.45,45.31$ with corresponding planes (101), (111), (221), (301) (223), (303), (441), (413), (224), (814), respectively. The high intense peaks at 23.30 and 24.04 is the characteristic peak for the MEL type framework topology which indicates the presence of ordered tetragonal crystal structure of ZSM-11 material [35]. Figure 1 (b) shows decreased peak intensities as compared Figure 1 (a) this may be due to insertion of cerium ion inside the channels of parent ZSM-11. However, crystal structure of parent ZSM-11 is retained after ion exchange.

3.1.2 Scanning electron microscopy-energy dispersive spectrometry analysis

The surface morphology and chemical composition of synthesized catalyst was analyzed by SEM-EDS spectroscopy. The Figure 2 shows uniform sphere shaped crystals which is characteristic morphology of ZSM-11. The SEM images show that prepared catalyst has uniform particle size and ordered morphology. The elemental composition Ce-ZSM-11 is shown in Figure 3 which confirms the presence of Si, Al, $\mathrm{O}$ and Ce with atomic wt. \% 29.82, 1.11, 67.82, 1.25 , respectively.

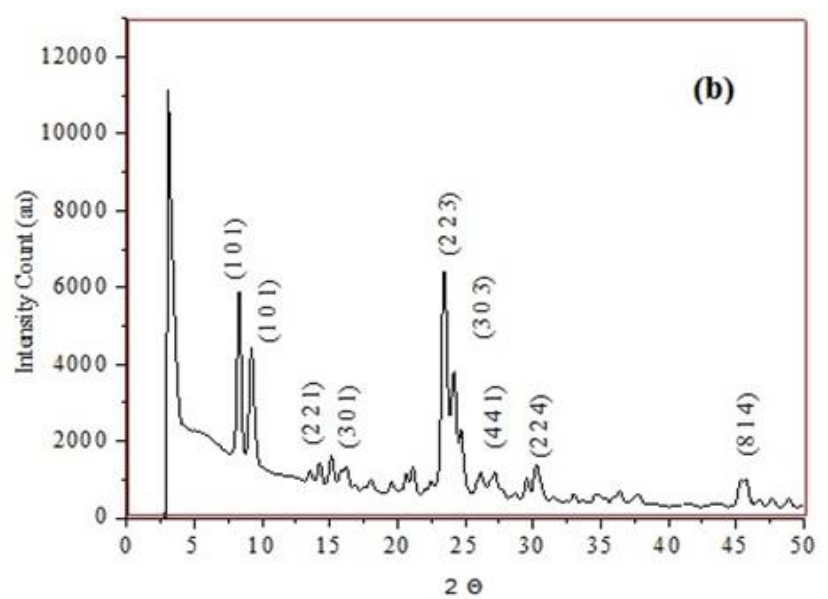

Figure 1. Powder XRD pattern of (a) ZSM-11 and (b) Ce-ZSM-11 
3.1.3 Fourier Transforms Infrared Spectroscopy analysis

The FT-IR spectrum of the ZSM-11 and Ce-ZSM-11 zeolite is shown in Figure 4. The FT-IR spectrum shows sharp peak at 451, 550, 798,1104 , and $1229 \mathrm{~cm}^{-1}$ which are characteristic adsorption bands of ZSM-11. The band at 798, 1229 assigned for external symmetric and asymmetric stretching vibration and sharp band at $1104 \mathrm{~cm}^{-1}$ is assigned to internal asym- metric stretching of $\mathrm{T}-\mathrm{O}-\mathrm{T}(\mathrm{T}=\mathrm{Si}$ or $\mathrm{Al})$ unit in ZSM-11 framework. The band at $550 \mathrm{~cm}^{-1}$ confirms the presence of double five member ring which is secondary building unit of pentasil family zeolites framework (MFI or MEL) [36]. The peak at $1635 \mathrm{~cm}^{-1}$ is attributed to deformation mode of Si-OH bond. The band appear between $3455 \mathrm{~cm}^{-1}$ confirms presence of bridged hydroxyl group, i.e. Brönsted acidic center.
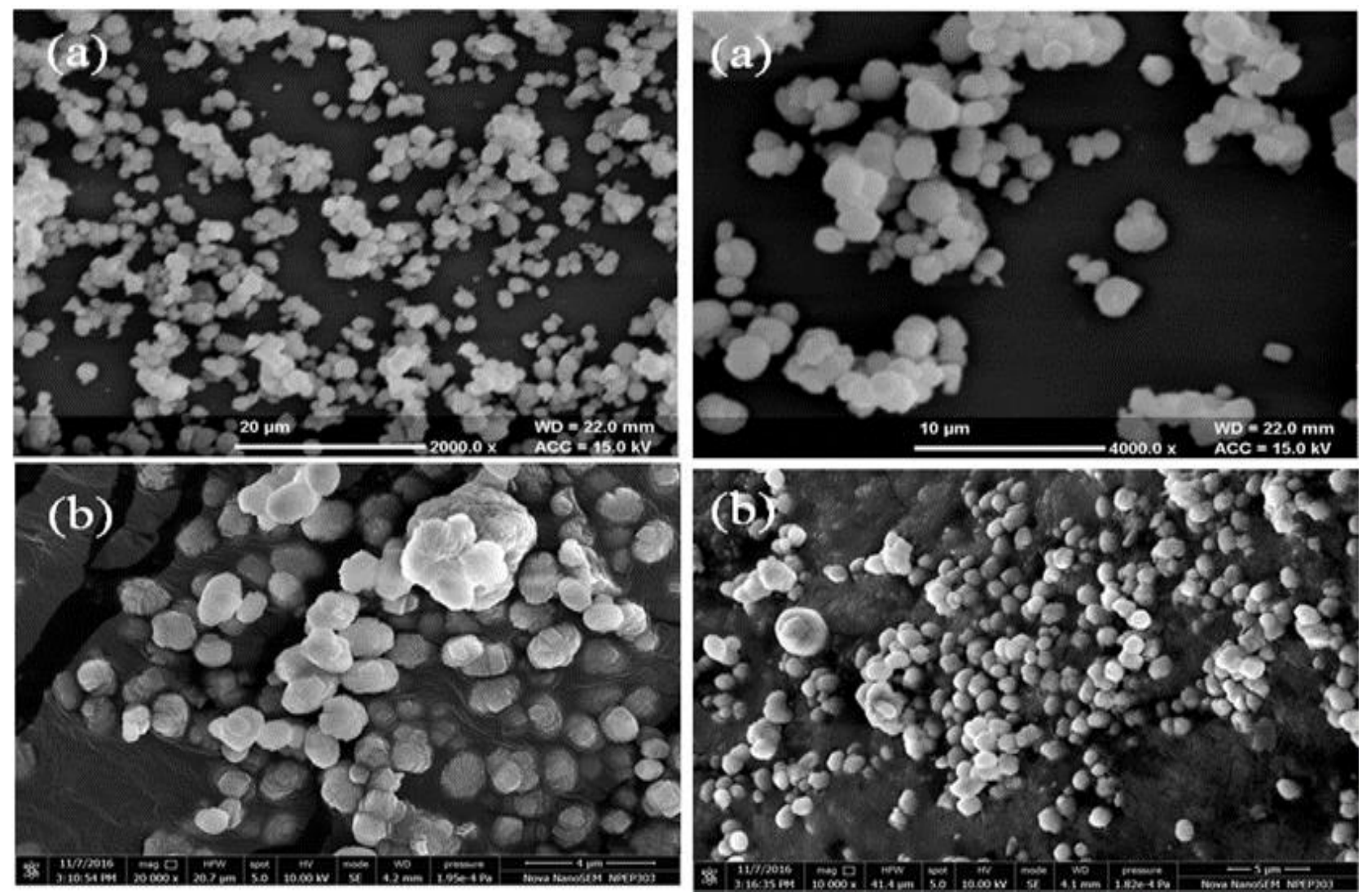

Figure 2. (a) SEM images of ZSM-11 zeolite and (b) SEM images of Ce-ZSM-11 zeolite

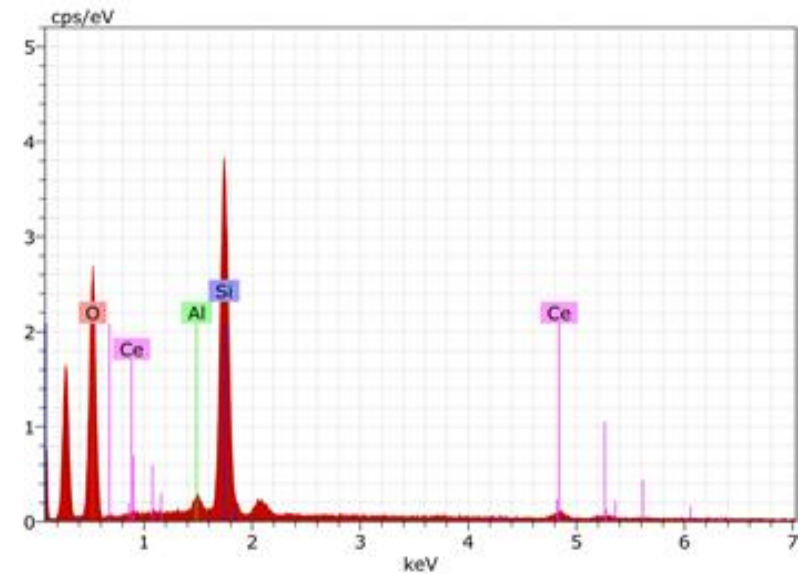

Figure 3. EDS-Spectrum of Ce-ZSM-11

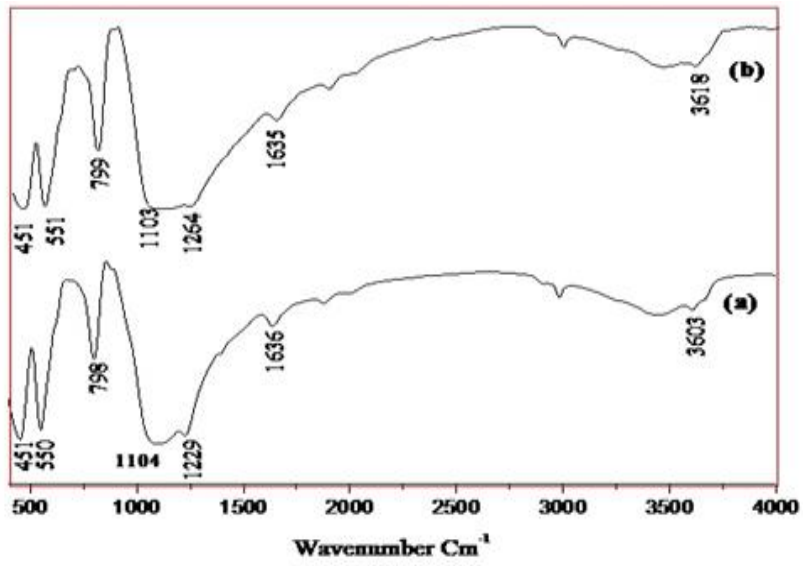

Figure 4. FT-IR Spectrum of (a) ZSM-11 and (b) Ce-ZSM-11 


\subsubsection{Brunauer-Emmer-Teller Surface Area analysis}

The presence of intercrystalline pore was studied by $\mathrm{N}_{2}$ adsorption-desorption isotherm. It is observed that surface area, micropore volume and average pore diameter of Ce-ZSM11 decreased as compared to ZSM-11 zeolite which implies that cerium ions are well dispersed in framework (Table 1).

\subsubsection{Temperature Programmed Desorption (Ammonia) analysis}

The Figure $5 \mathrm{a}$ and $5 \mathrm{~b}$ shows $\mathrm{NH}_{3}$-TPD profile of ZSM-11 and Ce-ZSM-11 zeolite. The single broad peak at $662.5{ }^{\circ} \mathrm{C}$ for ZSM-11 and $623.4^{\circ} \mathrm{C}$ for Ce-ZSM-11 is due to desorption of ammonia from strong acidic sites. The total acidity was found $1.8195 \mathrm{mmol.g}^{-1}$ and 2.6178 mmol.g-1 for ZSM-11 and Ce-ZSM-11, respectively. It was observed that the acidity of ZSM11 zeolite increases after ion exchange.

\subsection{Optimization of Reaction Conditions}

\subsubsection{Optimization of solvent and amount of} catalyst

In order to investigate suitable solvent and optimum loading of catalyst amount for the

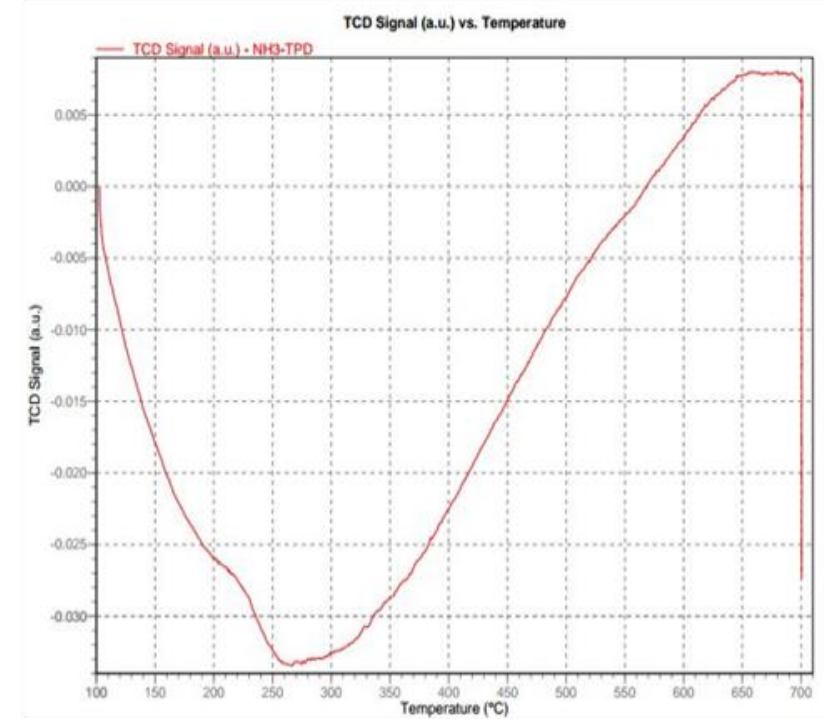

synthesis of 1,8-dioxo-octahydroxanthene derivatives, 3-nitro benzaldehyde $(1 \mathrm{mmol})$ and 5,5-dimethyl-cyclohexane-1,3-dione (2 $\mathrm{mmol})$ were taken as model substrate and various solvents were screened on model reaction. Initially the model reaction was performed under solvent free condition low yield of desired product was obtained. The same reaction was performed using different solvents such as, $\mathrm{EtOH}$, $\mathrm{MeOH}$, THF, and $\mathrm{H}_{2} \mathrm{O}$ under reflux condition. Among all these solvents in $\mathrm{H}_{2} \mathrm{O}$ maximum yield was obtained, hence $\mathrm{H}_{2} \mathrm{O}$ was selected as

Table 2. Effect of various solvent on the synthesis of synthesis of 1,8-dioxo-octahydroxanthene derivatives ${ }^{a}$

\begin{tabular}{cccc}
\hline Entry & Solvent & Time $(\min )$. & ${\text { Yield }(\%)^{\mathrm{b}}}^{\mathrm{b}}$ \\
\hline 1 & $\mathrm{No}$ & 120 & 30 \\
2 & $\mathrm{EtOH}$ & 120 & 30 \\
3 & $\mathrm{MeOH}$ & 120 & 20 \\
4 & $\mathrm{THF}$ & 120 & 35 \\
5 & $\mathrm{H}_{2} \mathrm{O}$ & 120 & 90 \\
\hline
\end{tabular}

aReaction conditions: 3-Nitro benzaldehyde $(1 \mathrm{mmol})$ and 5 , 5 dimethyl-cyclohexane-1,3-dione $(2 \mathrm{mmol})$ and catalyst with different solvents $(10 \mathrm{ml})$ at reflux condition. bIsolated yields.

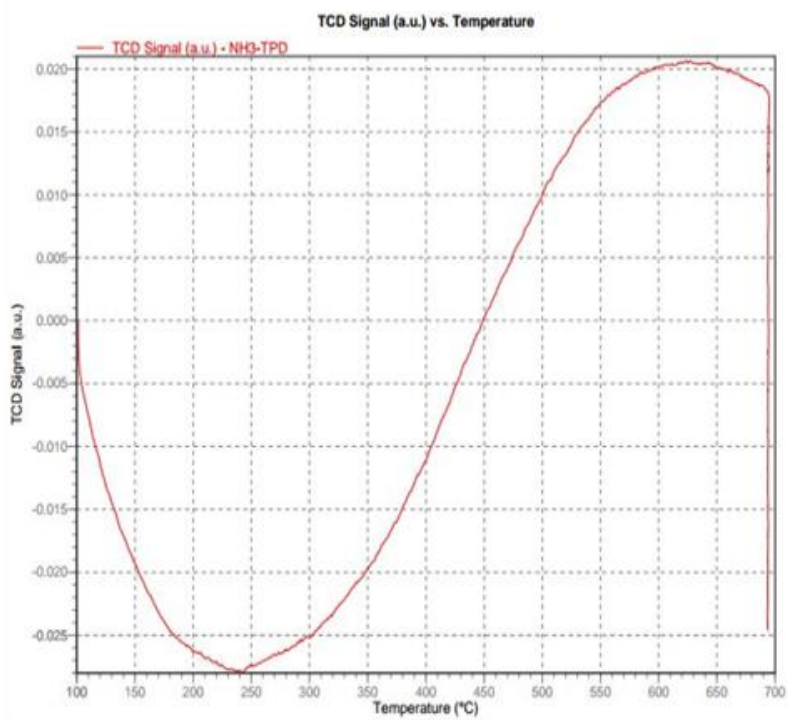

Figure 5. $\mathrm{NH}_{3}$-TPD Spectrum of (a) ZSM-11 and (b) Ce-ZSM-11

Table 1. BET surface area, micropore volume, and average pore diameter for ZSM-11 and Ce-ZSM-11

\begin{tabular}{clccc}
\hline Sr. No. & Sample & Surface area $\left(\mathrm{m}^{2 / \mathrm{g})}\right.$ & $\begin{array}{c}\text { Micropore volume } \\
\left(\mathrm{cm}^{3} / \mathrm{g}\right)\end{array}$ & Average pore diameter $(\AA)$ \\
\hline 1 & ZSM-11 & 641.37 & 0.52 & 16.37 \\
2 & Ce-ZSM-11 & 541.44 & 0.35 & 13.12 \\
\hline
\end{tabular}


optimum solvent (Table 2). Therefore, further optimization of catalyst was carried out in water solvent. It was observed that $0.1 \mathrm{~g}$ of catalyst is sufficient for the reaction and use of excessive catalyst had no effect on either the rate of reaction or on the product yield (Table 3).

The scope and efficiency of the present method was studied by reacting various substituted aromatic aldehyde with 5,5-dimethylcyclohexane-1,3-dione under optimize reaction conditions and results are summarized in Table 4. In all cases, it was found that aromatic aldehydes having electron withdrawing or electron donating group reacted effectively and gave the product in good yields. It is observed that the substituents in aromatic ring of aldehydes have little effect on the reaction time as well as yield of the product.

The main advantage of present method is reusability of Ce-ZSM-11 zeolite catalyst. The catalyst was separated after completion of reaction by diluting reaction mixture by hot ethanol and filtration. The recovered catalyst was washed with acetone and dried at $100{ }^{\circ} \mathrm{C}$ for 3 $\mathrm{h}$ before the next catalytic run. Reusability of the catalyst was investigated on model reaction for three times and it was found that the catalyst has retained almost consistent activity (Table 4, entry 3).

Table 3. Optimization of amount catalyst for the synthesis of of 1,8-dioxo-octahydroxanthene derivatives $^{\text {a }}$

\begin{tabular}{cccc}
\hline Entry & Catalyst amount $(\mathrm{g})$ & Time $(\min )$. & Yield $(\%)^{\mathrm{b}}$ \\
\hline 1 & 0 & 120 & - \\
2 & 0.05 & 120 & 85 \\
3 & 0.10 & 120 & 90 \\
4 & 0.15 & 120 & 90 \\
5 & 0.20 & 120 & 90 \\
\hline
\end{tabular}

aReaction condition: 3-trio benzaldehyde $(1 \mathrm{mmol})$ and 5,5 dimethyl-cyclohexane-1,3-dione $(2 \mathrm{mmol})$ and catalyst in water $(10 \mathrm{~mL})$ at reflux condition. ${ }^{\text {bs }}$ solated yields

Table 4. Ce-ZSM-11 catalyzed synthesis for 1,8-dioxo-octahydroxanthene derivatives ${ }^{a}$

\begin{tabular}{|c|c|c|c|c|c|c|}
\hline \multirow{2}{*}{ Entry } & \multirow{2}{*}{ Aldehyde (R) } & \multirow{2}{*}{ Product } & \multirow{2}{*}{$\begin{array}{l}\text { Time } \\
\text { (min.) }\end{array}$} & \multirow{2}{*}{ Yield $(\%)^{b}$} & \multicolumn{2}{|c|}{ M.P. $\left({ }^{\circ} \mathrm{C}\right)$} \\
\hline & & & & & Observed & Literature \\
\hline 1 & $\mathrm{H}$ & $3 a$ & 120 & 85 & $200-202$ & $203-204[15$ \\
\hline 2 & $4-\mathrm{NO}_{2}$ & $3 b$ & 120 & 88 & $226-228$ & $222-224[15$ \\
\hline 3 & $3-\mathrm{NO}_{2}$ & $3 \mathrm{c}$ & 120 & $90(90,85,85)^{\mathrm{c}}$ & $171-173$ & $172-174[19$ \\
\hline 4 & $4-\mathrm{Br}$ & $3 d$ & 120 & 88 & $240-243$ & $240242[19]$ \\
\hline 5 & $2-\mathrm{Br}$ & $3 e$ & 120 & 88 & $226-228$ & $225-227[18$ \\
\hline 6 & $4-\mathrm{OH}$ & $3 f$ & 120 & 80 & $248-250$ & $247-249[18$ \\
\hline 7 & $3-\mathrm{OH}$ & $3 g$ & 120 & 84 & $220-222$ & $222-224[18$ \\
\hline 8 & 4- $\mathrm{CH}_{3}$ & $3 \mathrm{~h}$ & 120 & 80 & $216-218$ & $215-217[18$ \\
\hline 9 & $2-\mathrm{NO}_{2}$ & $3 \mathrm{i}$ & 120 & 92 & $250-252$ & $248-250[18$ \\
\hline 10 & $4-\mathrm{N}\left(\mathrm{CH}_{3}\right)_{2}$ & $3 \mathrm{j}$ & 120 & 80 & $222-224$ & $221-223[14$ \\
\hline 11 & $4-\mathrm{Cl}$ & $3 \mathrm{k}$ & 120 & 90 & $229-231$ & $232-234[19$ \\
\hline
\end{tabular}

aReaction condition: $3-\mathrm{NO}_{2}$ benzaldehyde (1 mmol), 5,5 dimethyl-cyclohexane-1,3-dione ( 2 mmol) and catalyst $0.1 \mathrm{~g}$ in water $10 \mathrm{~mL}$. ${ }^{\mathrm{b}}$ Isolated yields. ${ }^{c}$ Yield after consecutive cycle. 
To specify the advantages of present methods, results of different reported methods are compared with present work and summarized in Table 5. It is observed that, Ce-ZSM-11 zeolite promote reaction more effectively than other reported catalyst.

\section{Conclusions}

In summary, we described the synthesis, characterization of ZSM-11 and Ce-ZSM-11 zeolite catalyst. The Ce-ZSM-11 zeolite was found efficient catalyst for the synthesis of 1,8-dioxooctahydroxanthene derivatives. The distinguished advantageous of present method are use of inexpensive catalyst, simple reaction workup, good to excellent yield, and reusability of catalyst.

\section{Acknowledgement}

We are grateful to the Head, Department of Chemistry, Dr. Babasaheb Ambedkar Marathwada University, Aurangabad-431004 (MS), India for providing the laboratory facility. The authors are thankful to STIC Cochin, CIF SPPU Pune, SAIF Chandigarh, CSMCRI Bhavnagar and IIT Madras for providing characterization facilities.

\section{References}

[1] Niknam, K., Borazjani, N., Rashidian, R., Jamali, A. (2013). Silica-bonded N- Propylpiperazine Sodium N-Propionate as Recyclable Catalyst for Synthesis of $4 \mathrm{H}$-Pyran Derivative. Chin. J. Catal., 34: 2245-2254.
[2] Domling, A., Ugi, I. (2000). Multicomponent Reaction with Isocyanides. Angew. Chem. Int. Ed., 39: 3168-3210.

[3] Kappe, C.O. (2000). Recent Advances in the Beginelli Dihydropyrimidone Synthesis. New Tricks from an Old Dog. Acc. Chem. Res., 33: 879-888.

[4] Zhu, J., Bienayme, H. (2005). Multicomponant Reaction. Weinheim;Wiley-VCH.

[5] El-Brashy, A.M., El-Sayed Metwally, M., ElSepai, F.A. (2004). Spectrophotometric Determination of Some Fluoroquinolone Antibacterial by Binary Complex Formation with Xanthene Dyes. Farmaco, 59: 809-817.

[6] Hafez, H.N., Hegab, M.I., Ahmed-Farag, I.S., El-Gazzar, A.B. (2008). A Facile Synthesis of Novel Spiro-Thioxanthene and SpiroXanthene-9', 2[1,3,4] Thiadiazole Derivatives as Potential Analgesic and AntiInflammatory Agents. Bioorg. Med. Chem. Lett., 18: 4538-4543.

[7] Poupelin, J.P., Saint-Ruf, G., FoussardBlanpin, O., Marcisse, G., Uchida-Earnauf, G., Lacroix, R. (1978). Synthesis and AntiInflammatory Properties of Bis(2-hydroxy-1naphthyl) Methane Derivatives. Eur. J. Med. Chem., 13: 67-71.

[8] Mulakayala, N., Murthy, P.V.N.S., Rambabu, D., Aeluri, M., Adepu, R., Krishna, G.R., Reddy, C.M., Prasad, K.R.S., Chaitanya, M., Kumar, C.S., Basaveswara Rao, M.V., Pal, M. (2012). Catalsis by Molecular Iodine: A Rapid Synthesis of 1,8 Dioxo-octahydroxanthenes and their Evaluation as Potential Anticancer Agents. Bioorg. Med. Chem. Lett., 22: 21862191.

Table 5. Comparison for synthesis methods 1,8-dioxo-octahydroxanthene derivatives with various reported catalyst

\begin{tabular}{cccccc}
\hline Entry & Catalyst & Condition & Time & Yield (\%) & Ref. \\
\hline 1 & Magnetic nps $\mathrm{Fe}_{3} \mathrm{O}_{4}$ & $\mathrm{H}_{2} \mathrm{O}, 80{ }^{\circ} \mathrm{C}$ & $8 \mathrm{~min}$. & $86-96$ & {$[12]$} \\
2 & $\mathrm{SiCl}_{4}$ & $\mathrm{DCE}, 60-70{ }^{\circ} \mathrm{C}$ & $3 \mathrm{~h}$ & $85-95$ & {$[13]$} \\
3 & $\mathrm{CaCl}_{2}$ & $\mathrm{DMSO}, 85-90{ }^{\circ} \mathrm{C}$ & $4 \mathrm{~h}$ & $80-93$ & {$[14]$} \\
4 & Imidazol-1-yl-acetic acid & Solvent free, $60{ }^{\circ} \mathrm{C}$ & $8-15 \mathrm{~min}$. & $85-95$ & {$[15]$} \\
5 & $\mathrm{CAN} / \mathrm{HY}-Z$ Zeolite & Solvent free, $80{ }^{\circ} \mathrm{C}$ & $90 \mathrm{~min}$. & $72-93$ & {$[16]$} \\
6 & $\mathrm{DSIMHS}$ & Solvent free, $55^{\circ} \mathrm{C}$ & $4 \mathrm{~min}$. & $88-94$ & {$[17]$} \\
7 & $\mathrm{ZnO} \mathrm{nps}$ & $\mathrm{EtOH}$, reflux & $90 \mathrm{~min}$. & $78-98$ & {$[18]$} \\
8 & $\mathrm{Ru@SH-MWCNT}$ & $\mathrm{EtOH}$, reflux & $30-60 \mathrm{~min}$. & $82-94$ & {$[19]$} \\
9 & $\mathrm{Fe}-\mathrm{Cu} / \mathrm{ZSM}-5$ & $\mathrm{H} 2 \mathrm{O},(((($ & $5-9 \mathrm{~min}$. & $90-96$ & {$[20]$} \\
10 & $\mathrm{Ce}-\mathrm{ZSM}-11$ & $\mathrm{H}_{2} \mathrm{O}$, reflux & $120 \mathrm{~min}$. & 90 & Present \\
& & & & result \\
\hline
\end{tabular}


[9] Murgra, D.C., Patel, M.P., Rajani, D.P., Patel, R.G. (2011). Synthesis and Identification of BAryloxyquinolines and their Pyrano[3,2-C] Chromene Derivatives as a New Class of Antimicrobial and Antituberculosis Agents. Eur. J. Med. Chem., 46: 4192-4200.

[10] Ahmad, M., King, T.A., Ko, D.K., Cha, B.H., Lee, J. (2002). Performance and Photostability of Xanthene and Pyrromethene Laser Dyes in Sol-Gel Phases. J. Phys. D. Appl. Phys., 35: 1473-1476.

[11] Hilderbrand, S.A., Weissleder, R. (2007). Onepot Synthesis of New Symmetric and Asymmetric Xanthene Dyes. Tetrahedron Lett., 48: 4383- 4385.

[12] Karami, B., Jafar Hoseini, S., Eskandari, K., Ghasemi, A., Nasrabadi, H. (2012). Synthesis of Xanthene Derivatives by Employing $\mathrm{Fe}_{3} \mathrm{O}_{4}$ Nanoparticles as an Effective and Magnetically Recoverable Catalyst in Water. Catal. Sci. Technol., 2: 331-338.

[13] Soliman, H.A., Salama, T.A. (2013). Siliconmediated Highly Efficient Synthesis of 1,8 Dioxo-octahydroxanthenes and their Transformation to Novel Functionalized Pyranotetrazolo [1,5-A] Azepine Derivatives. Chinese Chemical Lett., 24: 404-406.

[14] Ilangovan, A., Muralidharan, S., Sakthivel, P., Malayappasamy, S., Karuppusamy, S., Kaushik, M.P. (2013). Simple and Cost Effective Acid Catalysts for Efficient Synthesis of 9-Aryl-1,8 Dioxooctahydroxanthene. Tetrahedron Lett., 54: 491- 494.

[15] Nazari, S., Keshavarz, M., Karami, B., Iravani, N., Vafaee-Nezhad, M. (2014). Imidazol-1yl-acetic Acid as a Novel Green Bifunctional Organocatalyst for the Synthesis of 1, 8Dioxooctahydroxanthene under Solvent Free Condition. Chinese Chemical Lett., 25: 317320 .

[16] Sivaguru, P., Lalitha, A. (2014). Ceric Ammonium Nitrate Supported HY-Zeolite: An Efficient Catalyst for the Synthesis of 1,8Dioxooctahydroxanthene. Chinese Chemical Lett., 25: 321-323.

[17] Shirini, F., Yahyazadeh, A., Mohammadi, K. (2014). One-pot Synthesis of Various Xanthene Derivatives using Ionic Liquid 1,3Disulfonic Acid Imidazolium Hydrogen Sulfate as an Efficient and Reusable Catalysts under Solvent Free Condition. Chinese Chemical Lett., 25: 341-347.

[18] Lasemi, Z., Mehrasbi, E. (2015). ZnO Nanoparticles: An Efficient and Reuasable Catalyst for One-pot Synthesis of 1,8-Dioxooctahydroxanthene. Res. Chem. Intermed., 41: 2855-2866.
[19] Tabatabaeian, K., Zanjanchi, M.A., Mamaghani, M., Dadashi, A. (2016). Ruthenium Anchored on Multi-walled Arbon Nanotubes: An Efficient and Reusable Catalyst for the Synthesis of Xanthene. Res. Chem. Intermed., 42: 5049-5067.

[20] Safa, K.D., Taheri, E., Allahvirdinesbat, M., Niaei, A. (2016). Sonochemical Synthesis of Xanthene Derivative using Zeolite Supported Transition Metal Catalyst in Aqueous Media. Res. Chem. Intermed., 42: 2989-3004.

[21] Rana, V., Kanagaraj, K., Pitchamani, K. (2012). A Multicomponent, Solvent Free, Onepot Synthesis of Benzoxanthenone Catalyzed by HY Zeolite: Their Anti-Microbial and Cell Imaging Studies. Tetrahedron Lett., 53: 10181024.

[22] Yu, Q., Chen, J., Zhang, Q., Li, C., Cui, Q. (2014). Micron ZSM-11 Microsperes Seedassisted Synthesis of Hierarchiral Submicron ZSM-11 with Intergrowth Morphology. Mater. Lett., 120: 97-100.

[23] Yu, Q., Li, C., Tang, X., Yi, H. (2016). Effect of Seeding on the Fast Crystallization of ZSM-11 Microspheres with Intergrowth Morphology and Small Particle Size. J. Porous Mater., 23: 273-284.

[24] Bleken, F., Skistad, W., Barbera, K., Kustova, M., Bordiga, S., Beato, P., Lillerud, K.P., Svelle, S., Olsbye, U. (2011). Conversion of Methanol over 10-Ring Zeolites with Differing Volume at Channel Intersections: Comparison of TNU-9, IM-5, ZSM-11 and ZSM-5. Phys. Chem. Chem. Phys., 13: 2539-2549.

[25] Zhang, L., Liu, H.J., Li, X.J., Xie, S.J., Wang, Y.Z., Xin, W.J., Liu, S.L., Xu, L.Y. (2010). Differences between ZSM-5 and ZSM-11 Zeolite Catalyst in 1-Hexane Aromatization and Isomerization. Fuel Process. Technol., 91: 449-455.

[26] Bortnovsky, O., Sazama, P., Wichterlova, B. (2005). Cracking of Pentenes to $\mathrm{C}_{2}-\mathrm{C}_{4}$ Light Olefins over Zeolite and Zeotypes: Role of Topology and Acid Site Strength and Concentration. Appl. Catal. A, 287: 203-213.

[27] Meng, X., Huang, H., Zhang, Q., Zhang, M., Li, C., Cui, Q. (2016). Conversion of Methanol into Light Olefins over ZSM-11 Catalyst in a Circulating Fluidized-bed Unit. Korean J. Chem. Eng., 33: 831- 837.

[28] Gomez, S., Lerici, L., Saux, C., Perez, A.L., Brondino, C.D., Pierella, L., Pizzio, L. (2017). Fe/ZSM-11 as a Novel and Efficient Photo Catalyst to Degrade Dichlorvos on Water Solution. Appl. Catal. B Environ., 202: 580- 586.

[29] Xie, P., Ma, Z., Zhou, H., Huang, C., Yue, Y., She, W., Xu, H., Hua, W., Gao, Z., (2014). Catalytic Decomposition of $\mathrm{N}_{2} \mathrm{O}$ over $\mathrm{Cu}$ - 
ZSM-11 Catalyst. Microporous Mesoporous Mater., 191: 112-117.

[30] Anunziata, O.A., Mercado, G.V.G., Pierella, L.B. (2003). Catalytic Activation of Methane using N-Pentane as Co-reactant over $\mathrm{Zn} / \mathrm{H}$ ZSM-11 Zeolite. Catalysis Lett., 87: 167-171.

[31] Anunziata, O.A., Cussa, J., Beltramone, A.R. (2011). Simultaneous Optimization of Methane Conversion and Aromatic Yields by Catalytic Activation with Ethane over ZnZSM-11 Zeolite: The Influence of the Zn Loading Factor. Catal. Today., 171: 36-42.

[32] Lerici, L.C., Renzini, M.S., Sedran, U., Pierella, L.B. (2013). Tertiary Recycling of Lowdensity Polyethylene by Catalytic Cracking over ZSM-11 and BETA Zeolites Modified with $\mathrm{Zn}^{2+}$ : Stability Study. Energy Fuels, 27: 2202-2208.
[33] Magar, R.R., Pawar, G.T., Arbad, B.R., Lande, M.K. (2016). Fe-MCM-22: An Efficient Heterogeneous Catalyst for One Pot Four Component Synthesis of 1H-pyrazolo [1, 2-b] phthalazine-5,10-dione Derivatives. Adv. Org. Chem. Lett., 3: 8-14

[34] Magar, R.R., Pawar, G.T., Gadekar, S.P., Lande, M.K. (2017). Fe-MCM-22 Catalyzed Multicomponent Synthesis of Dihydropyrano[2,3-c] pyrazole Derivatives, Iran. J. Catal., 7: $1-9$.

[35] Treacy, M.M.J., Higgins, J.B., (2001). Collection of Simulated XRD Powder Patterns for Zeolite, New York, NY: Elsevier

[36] Yu, Q., Cui, C., Zhang, Q., Chen, J., Li, Y., Sun, J., Li, C., Cui, Q., Yang, C., Shan, H. (2013). Hierarchical ZSM-11 with Intergrowth Structure: Synthesis, Characterization and Catalytic Properties. Journal of Energy Chemistry, 22: 761-768. 


\section{APPENDICES}

3,3,6,6 Tetramethyl-9-(3-nitro-phenyl)-3,4,5,6,7,9-hexahydro-2H-Xanthene-1,8-dione (3c)

FT-IR (KBr, cm-1): 2955, 2874, 1708, 1584, 1452,
1363
${ }_{\mathbf{1}} \mathbf{H} \mathbf{N M R}(\mathbf{4 0 0} \mathbf{M H z}, \mathbf{D M S O}-\mathbf{d} \mathbf{6}) \mathbf{2} \delta(\mathrm{ppm})=8.05(\mathrm{~s}$,
$1 \mathrm{H}), 7.97(\mathrm{~d}, \mathrm{~J}=8.1 \mathrm{~Hz}, 1 \mathrm{H}), 7.63(\mathrm{~d}, \mathrm{~J}=7.7 \mathrm{~Hz}, 1 \mathrm{H})$,
$7.48(\mathrm{t}, \mathrm{J}=7.9 \mathrm{~Hz}, 1 \mathrm{H}), 4.67(\mathrm{~s}, 1 \mathrm{H}), 2.56(\mathrm{~s}, 4 \mathrm{H}), 2.09$
$(\mathrm{~s}, 4 \mathrm{H}), 1.08(\mathrm{~s}, 6 \mathrm{H}), 0.9(\mathrm{~s}, 6 \mathrm{H})$
$\mathbf{1 3} \mathbf{C} \mathbf{M R}(\mathbf{4 0 0} \mathbf{M H z}, \mathbf{D M S O}-\mathbf{d} \mathbf{6}): 26.61,28.61$,
$31.63,39.57,49.94,113.48,121.17,122.70,129.08$,
$134.55,146.27,147.39,163.14,195.74$

FT-IR spectrum of 3,3,6,6 Tetramethyl-9-(3-nitro-phenyl)-3,4,5,6,7,9-hexahydro-2H-Xanthene-1,8dione (3c)

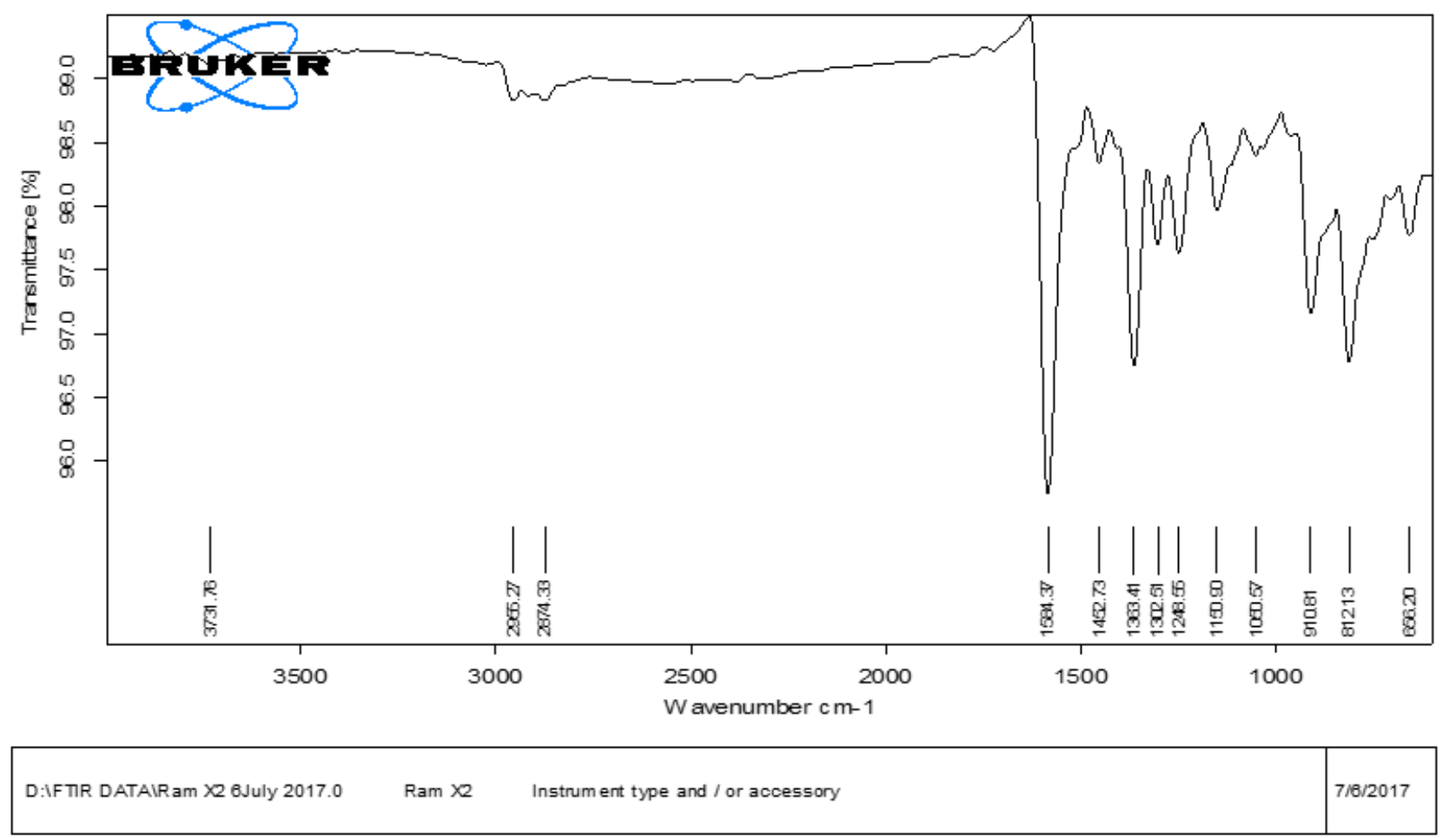


${ }^{1} \mathrm{H}$ NMR spectrum of 3,3,6,6 Tetramethyl-9-(3-nitro-phenyl)-3,4,5,6,7,9-hexahydro-2H-Xanthene-1,8dione $(3 \mathbf{c})$

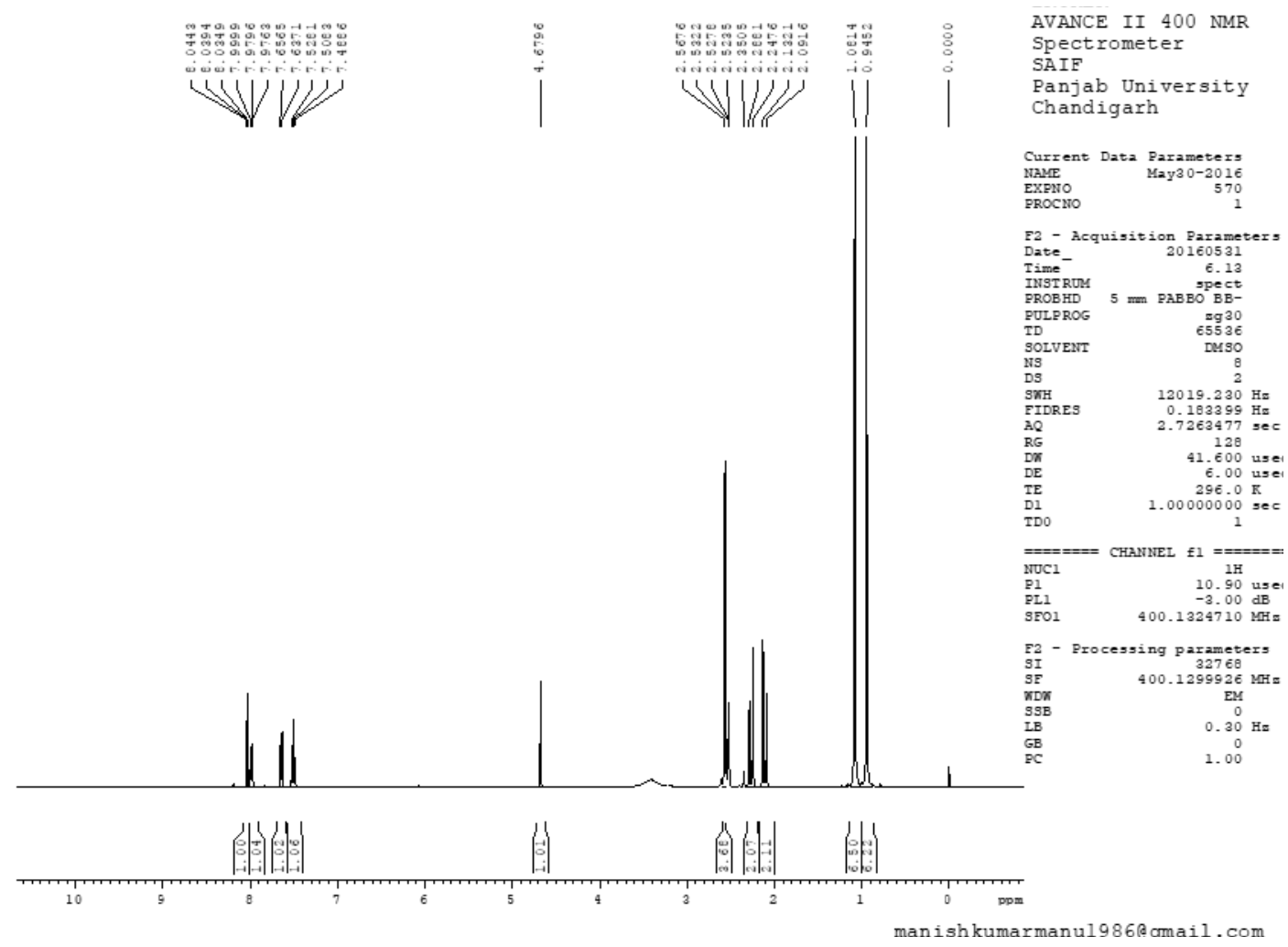

${ }^{13} \mathrm{C}$ NMR spectrum of 3,3,6,6 Tetramethyl-9-(3-nitro-phenyl)-3,4,5,6,7,9-hexahydro-2H-Xanthene-1,8dione (3c)

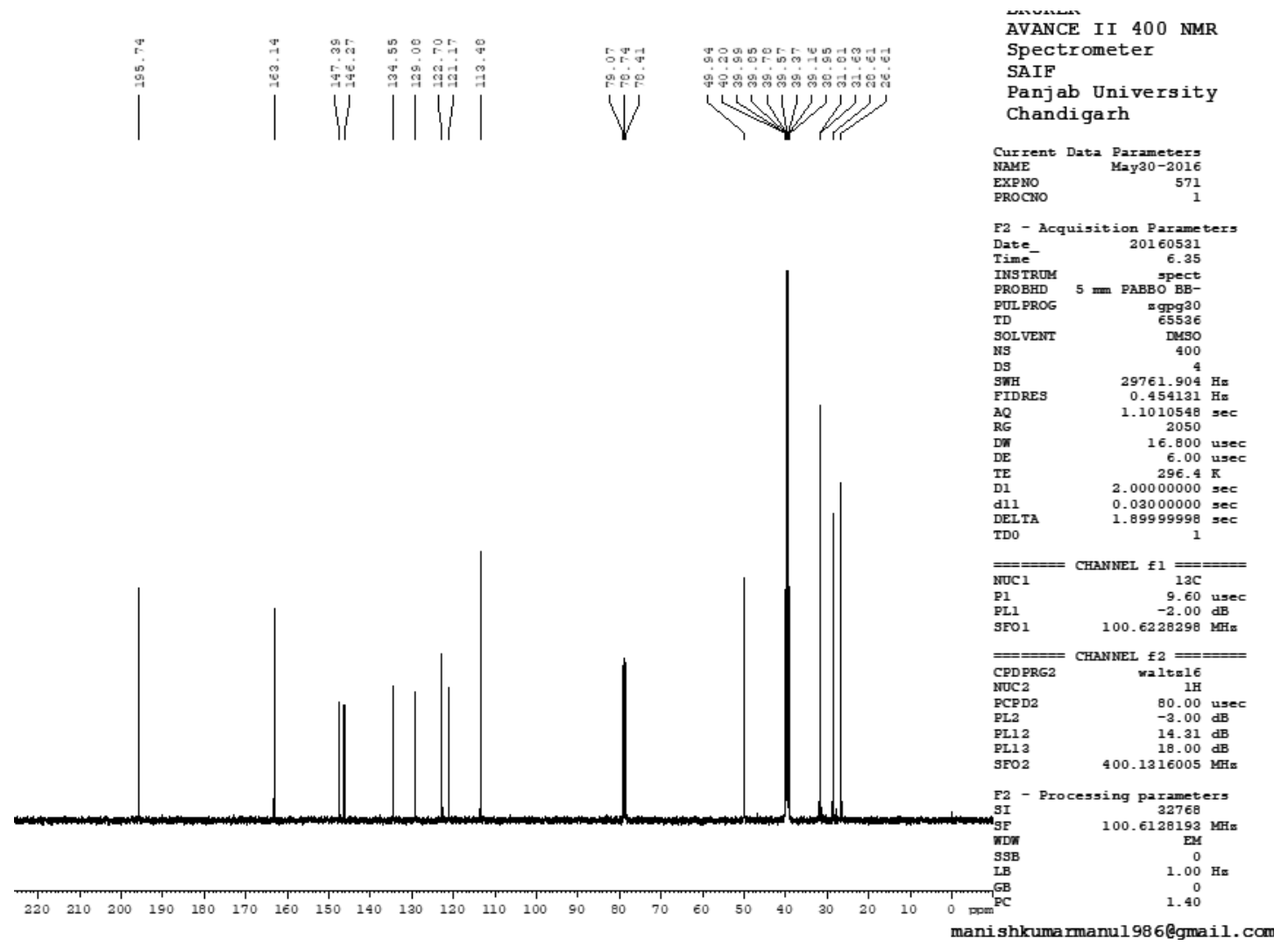

